\title{
Los padres de familia ante el consumo de televisión de sus hijos
}

\author{
Juan Camilo Díaz Bohórquez ${ }^{1}$ \\ Iván Darío Moreno Acero ${ }^{2}$
}

Recibido: 03-11-2019

Aceptado: 06-05-2020

\section{Resumen}

Con el objetivo de caracterizar los hábitos, preferencias y roles de los padres de familia frente al consumo de televisión de sus hijos, se realizó una investigación con 70 padres de un hogar infantil de la ciudad de Bogotá, con quienes se trabajó una metodología investigativa mixta en la que se combinaron entrevistas a profundidad y cuestionarios. Los resultados de esta investigación llevaron a evidenciar que es necesario fortalecer el criterio con el que los padres le otorgan valor y sentido a la televisión dentro de una de las etapas más importantes del desarrollo de sus hijos.

Palabras clave: televisión, infancia, familia, roles, hábitos.

\footnotetext{
1. Magíster en Educación, Especilialista en Pedagogía para el Desarrollo del Aprendizaje Autónomo y Comunicador Social. Docente, Coordinador de Comunicaciones, Instituto de La Familia, Universidad de La Sabana.

Correo electrónico: juan.diaz7@unisabana.edu.co

ORCID: https://orcid.org/0000-0002-6129-751X

Cvlac: http://scienti.colciencias.gov.co:8081/cvlac/visualizador/generarCurriculoCv. do?cod_rh=0001300474

Google Scholar: https://scholar.google.com/citations?view_op=list_ works\&hl=es\&user=9wj__4kAAAAJ

2. Doctor(c) en Estudios Sociales, Magíster en Educación y Licenciado en Filosofía. Investigador, Coordinador de Investigaciones y Líder del Grupo de Investigación Familia y Sociedad, Instituto de La Familia, Universidad de La Sabana.

Correo electrónico: ivanma@unisabana.edu.co

orcid: https://orcid.org/0000-0003-1308-6184

Cvlac: http://scienti.colciencias.gov.co:8081/cvlac/visualizador/generarCurriculoCv. do?cod_rh=0000722081

Google Scholar: https://scholar.google.es/citations?user=nfbOyYkAAAAJ\&hl=es
} 


\section{Parents facing their children's television consumption}

\section{Abstract}

In order to characterize the habits, preferences and roles of parents in relation to their children's television consumption, an investigation was carried out with 70 parents from a children's home in the city of Bogotá, with whom a mixed investigative methodology was used. in which in-depth interviews and questionnaires were combined. The results of this research led to evidence that it is necessary to strengthen the criteria with which parents give value and meaning to television within one of the most important stages of their children's development.

Keywords: television, childhood, family, roles, habits.

\section{Introducción}

La televisión ha traído notables cambios en la forma como se ve y asume la vida ya que llega a todos los hogares, sin importar la clase social y la edad. Hay coincidencia en afirmar que la televisión es, dentro de la cultura mediática, uno de los medios más significativos y de mayor relevancia, aun con la embestida que ha significado la entrada de otras pantallas como los dispositivos móviles conectados a internet. Así como se encuentran posturas que aseguran que la televisión es una herramienta de divulgación, entretenimiento y educación, para otros es la culpable de los males de la sociedad (Díaz, 2014).

De la televisión se dice que es capaz de construir y destruir, de crear los ídolos que dan sentido a la vida. Sin embargo, de acuer- 
do con Cabero (1997), "no debemos olvidar, por una parte, que todo medio no funciona en el vacío, sino dentro de un contexto físico, cultural e ideológico [...] y por otra, los sujetos no somos procesadores pasivos de la información, sino constructores activos de la misma" (p. 69).

La televisión tiene características como ser multicanal, segmentada, temática y tener una parrilla amplia e ilimitada, lo cual permite el desarrollo de audiencias activas con múltiples interpretaciones de lo que ven y escuchan. En el caso de los niños, la televisión les permite separarse del mundo adulto y de la realidad mediata, ya que ver televisión es un juego, gozan interpretando el contenido que de alguna forma usan en su vida cotidiana. Este asunto debe ser mirado con lupa porque los niños tienen una incompleta formación social, cultural y de valores, lo cual los hace un público vulnerable (Gutiérrez, 1990; Sedeño, 2005; Valle, 2006).

Según Wartella, Ritcher y Robb (2010), los niños menores de tres años comenzaron a ver televisión desde la década de los cincuenta en Estados Unidos y ese proceso ocurrió en diferentes lugares en diferentes momentos, dependiendo de las condiciones socioeconómicas, políticas, sociales y culturales del lugar. Rodríguez (2011) ratifica lo anterior cuando señala que desde el momento de la llegada de la televisión a los ambientes domésticos se dio inicio a la relación niños-televisión.

Los padres de familia viven preocupados por el impacto de la televisión en sus hijos. Su influencia es muy fuerte, pareciera que no hay herramientas suficientes para enfrentar su poder, especialmente cuando los niños se encuentran entre los 3 y 5 años, tiempo de pleno desarrollo emocional, cognitivo, físico y de más apego, voluntaria o involuntariamente, a la televisión.

En un estudio realizado sobre televisión y contextos sociales, Albero (1996) afirma que la televisión es parte de la vida cotidiana de niños y niñas y la forma en que la utilizan no está modelada solo por los propios contenidos televisivos, sino también por el uso y la comprensión individual de esos contenidos. Así, es claro 
que es necesario criticar a la televisión, pero a la vez se le delegan funciones:

La "niñera electrónica", muchas veces, se hace cargo de entretener por su cuenta a los hijos mientras sus padres están en el trabajo o en otras actividades. Se le ha llamado el "tercer padre", porque puede llegar a ejercer una autoridad tan importante como del padre o la madre. También se le denomina "escuela paralela". (Yarce, 1993, p. 30)

Con el tiempo ha surgido la necesidad de saber administrar la televisión, conocer qué rol tiene en casa. Una investigación realizada por María Josefa Domínguez, citada por Gustavo Castro en Aprendamos a ver TV (2007), estableció que "el 98 por ciento de los padres de familia colombianos no sabe cómo manejar adecuadamente la televisión en el hogar, y aunque están interesados en aprenderlo, nadie les enseña" (p. 5).

En este punto es necesario hacer varias preguntas: ¿Están los padres capacitados para guiar a los niños en este proceso? ¿Cuáles son los roles que asumen frente al consumo de televisión de sus hijos? ¿Qué papel cumple la televisión en casa? Las investigaciones sobre la televisión y sobre la relación niños-televisión han pasado por diferentes etapas y paradigmas que van desde la aguja hipodérmica, la persuasión del medio, los efectos secundarios, los estudios culturales y las teorías comunicativas. Para Wolf (1994), las tres corrientes de estudio más importantes acerca de la televisión han sido la hipodérmica, los efectos limitados y los efectos a largo plazo.

Por otro lado, está la mirada funcionalista (Río, Río y Álvarez, 2004, p. 187), corriente que indica que no solamente se deben estudiar los efectos de la televisión en la manera de ver el mundo, sino observar las funciones que los medios de comunicación de masas, liderados por la televisión, tienen en la sociedad. Esta corriente parte de la premisa según la cual no se puede entender la sociedad sin entender los medios que en ella se desarrollan. 
En términos generales, y sin que eso signifique que aquí se agota la discusión, estas son las grandes tendencias de investigación alrededor de la televisión:

- Perfiles de las audiencias de acuerdo con edad, nivel socioeconómico, nivel cultural y géneros televisivos.

- Consumo de televisión respecto a consumo de otros medios y pantallas.

- Consumo de televisión, ocio y tiempo libre.

- Consumo de televisión, rendimiento escolar, manejo de vocabulario, desarrollo psicomotriz, imaginarios, creatividad, etc.

- Relación entre violencia y consumo de televisión con altos contenidos de violencia.

- Efectos del consumo de la televisión, especialmente en los niños: realidad, imitación, comportamientos, conductas.

- Impacto en la percepción de grupos minoritarios, instituciones, definiciones, etc.

- Expansión de la industria audiovisual y sus posibles repercusiones en el desarrollo de los niños.

Como se observa, no son frecuentes los estudios que abarquen el rol de los padres de familia frente al consumo de televisión, ante lo cual es necesario preguntar: ¿Por qué deberían abordarlos? ¿Por qué estudiar la relación niños-televisión desde la perspectiva de la familia?

Nunca se debe perder de vista que los padres tienen la responsabilidad de educar a sus hijos $y$, por ende, de decidir sobre las formas en que se consumen los contenidos televisivos. De esta 
manera, desde una perspectiva que incluye el análisis del papel que cumplen los padres de familia, se aborda la relación niñostelevisión. En función de ello, esta investigación se propuso, en primer lugar, caracterizar el rol que desempeñan los padres de familia de un hogar infantil, ubicado en Bogotá, frente al consumo de televisión de sus hijos/as con edades entre los 3 y 5 años. En segundo lugar, la investigación propone un taller de formación que motive la reflexión de los padres e hijos frente a la televisión que consumen cotidianamente.

La familia es el fundamento de toda sociedad, pues es la primera institución que se encarga de la socialización inicial de todos sus miembros (Coloma, 1993, p. 31). En consecuencia, tiene la obligación de introducir a los hijos en los ambientes más valiosos de la vida, en cómo descubrir los bienes trascendentes, e iniciarlos en el amor, la vida, el dolor, el sufrimiento, el prójimo, el trabajo, la convivencia y la solidaridad.

Los padres enseñan los principios y valores sociales a sus hijos por dos vías: por lo que dicen y por lo que hacen, y por lo que no dicen y no hacen. Si ciertos principios -como la honradez, el servicio, la solidaridad, el respeto, el amor al trabajo y la cortesía- han sido manejados por los padres y forman parte de los valores familiares, es muy probable que se transmitan a sus hijos (Altarejos, 2002; Comellas, 2009).

Por tanto, los padres deben asumir consciente y responsablemente su tarea de educar a los hijos en medio de un mundo confuso y cambiante, que todos los días exige nuevas y renovadas orientaciones. Esta situación no acepta improvisaciones y obliga a mantener una disposición para buscar información y prepararse para desempeñar la tarea educativa en forma adecuada, ya que el futuro dependerá de la forma como se realice esta misión.

Sin embargo, para alcanzar esas metas son necesarios muchos conocimientos psicológicos y pedagógicos y, sobre todo, hay que hacer uso del ejemplo como medio de transmisión de los valores y virtudes. Sin embargo, en muchas ocasiones se dejan de lado las 
obligaciones educativas parentales y se delegan comúnmente a la televisión, que en muchas ocasiones distorsiona los ideales de vida, sociedad y familia que la sociedad requiere.

\section{Metodología}

\section{Aspectos generales}

Teniendo en cuenta el objeto de investigación y nuestro campo de estudio, aplicamos una metodología mixta que buscó obtener información de carácter cualitativo y cuantitativo de los padres de familia, responsables de la educación de sus hijos y mediadores de estos con el televisor. Para Sampieri, Fernández y Baptista (2010), "la meta de la investigación mixta no es remplazar a la investigación cuantitativa ni a la investigación cualitativa, sino utilizar las fortalezas de ambos tipos de indagación combinándolas y tratando de minimizar sus debilidades potenciales" (p. 544).

\section{Población y muestra}

La población estuvo conformada por 70 padres de familia de un hogar infantil ubicado en Bogotá. La selección del jardín infantil obedeció a la presencia de niños y niñas con edades entre los 3 y los 5 años. Se escogió esta población en esta edad porque, de acuerdo con diferentes estudios, es uno de los momentos de mayor importancia en el desarrollo mental e intelectual. El muestreo no probabilístico utilizado para la selección de la población fue intencional o por conveniencia, pues la selección de los participantes fue deliberada y tenía la intención de incluir la generalidad del grupo mayoritario, en este caso familias nucleares.

\section{Instrumento}

Para cumplir los propósitos del estudio se emplearon las siguientes técnicas de investigación: encuesta orientada, en donde el investigador se aseguró de orientar el sentido de cada pregunta; y grupo 
focal, en donde, una vez diligenciado el instrumento, se conversó (entrevista) con el grupo de padres frente al tema objeto de estudio, para complementar la información depositada.

Los aspectos determinados por la encuesta fueron la identificación de la familia, la relación familia-televisión, la importancia de la televisión para la familia, hábitos de consumo de televisión, impacto de la televisión y el rol que los padres de familia asumen frente al consumo de televisión de sus hijos.

Se diligenciaron 43 encuestas que corresponden al $61,42 \%$ del total de actores consultados. El 90,69 \% de las familias encuestadas tiene al menos un niño o niña con edades entre los 3 y 5 años, solamente 4 tienen dos hijos/as en ese rango de edad (9,30\%). De las 43 familias encuestadas, el $60,47 \%$ de sus hijos son hombres (26 niños) y el restante $39,53 \%$ son mujeres (17 niñas).

\section{Resultados y análisis}

La televisión es el símbolo de la cultura de masas, ha irrumpido en todos los lugares, comenzando por los hogares. Ese poder de la televisión radica en muchos factores, pero sobre todo en el hecho de que permite que los telespectadores puedan aprovecharla a distintos niveles, independientemente de sus recursos, formación, expectativas y necesidades. De allí que sea indudable el valor que la televisión posee para crear espacios de diálogo y para influir en el funcionamiento de las sociedades. De forma un tanto inexplicable, los telespectadores se sienten anclados a la realidad precisamente a través de la información que llega a sus hogares (Ramírez, 2006).

Los padres pueden asumir diversas actitudes frente al consumo de televisión de sus hijos/as. Están los permisivos, quienes aceptan que sus hijos/as vean cualquier programa ya que la televisión tiene una función de "niñera" en el hogar; los represivos, aquellos que consideran que la televisión es un enemigo en casa y que prohíben que sus hijos/as la vean; $y$, por último, existen los padres preocu- 
pados por el tema, que buscan conversar sobre los contenidos, a pesar que nunca fueron formados como receptores críticos. Castro (2007) da un valor fundamental a aquellos padres interesados, ya que la autoridad bien ejercida, que selecciona los programas y establece una disciplina horaria en el consumo de la televisión, puede ser muy efectiva como medio de convencimiento y no de represión.

\section{El rol de la madre y la ausencia del padre frente al consumo de televisión de sus hijos/as: conciencia en medio del desinterés}

Llama la atención que más del $87 \%$ de las encuestas y las entrevistas fueron atendidas por las mamás. Es claro que la madre cumple un papel fundamental en la estructura familiar, al menos en la edad que cubría el estudio (3 a 5 años). Lo anterior se debe a que la relación "padre-oficina" y "mamá-hogar" se mantiene dentro de nuestra cultura, en donde el hombre delega buena parte de la responsabilidad de la formación de los hijos. En otras palabras, a pesar de trabajar y poder llegar a ser muy exitosa laboralmente, la mujer mantiene culturalmente una marca de que su principal trabajo, independientemente de los otros, es el hogar y la crianza de los hijos.

Horarios cruzados: ¿en quién recae la responsabilidad de la mediación niños-televisión?

El estudio arrojó que papá y mamá trabajan en promedio 9 horas diarias entre semana más una media de 3,5 horas nocturnas. Los fines de semana hay una media de 6 horas diurnas sin horas nocturnas. Si se tiene en cuenta que el horario del hogar infantil estudiado, y en términos generales de los colegios de Bogotá, es de 8 a 4 p. m. entre semana, es decir 8 horas diarias, se encuentra que mientras los niños están estudiando los padres trabajan. Pero esos horarios no siempre coinciden al finalizar la tarde, por lo que, mientras llegan a casa sus padres, los niños están con la niñera o con algún familiar, quienes utilizan la televisión como distractor mientras realizan otras actividades. 


\section{La educación formal puede facilitar la formación audiovisual}

Del total de las encuestas resueltas, se destaca que el 55,81\% de los padres encuestados pertenece al estrato 4, seguido por el 30,23 $\%$ del estrato 3 y el 13,96 \% que no respondió a esta pregunta. Según la Gran Encuesta de la Televisión en Colombia, que adelantó la Comisión Nacional de Televisión en el 2008, es común que en estos hogares haya por lo menos dos televisores. Este punto es relevante ya que los niveles de estudio (técnicos, tecnológicos, universitarios y de formación posgradual), pueden facilitar un proceso de formación en recepción crítica de televisión en el hogar, puesto que existirían hábitos de evaluación crítica de los fenómenos sociales y criterios de elección de consumos de los contenidos culturales.

\section{La televisión: un importante miembro de la familia}

Para 30 padres de familia $(69,76 \%)$ la televisión es muy importante, 9 familias (20,93 \%) aseguran que es poco importante y el 9,30\% considera que es nada importante. Ahora bien, esos padres consideran que la televisión es un medio que entretiene $(46,52 \%)$, informa $(37,20 \%)$, integra a la familia $(9,30 \%)$ y educa $(6,98 \%)$. Ninguna familia considera que la televisión sea un medio que separa a la familia. Las razones más importantes son: mientras comparten en familia, se entretienen, divierten e informan. Sin embargo, hay que tener en cuenta que las familias que aseguran que la televisión es poco importante argumentan que los contenidos no son adecuados. Aquí se evidencia aun más la importancia que cobra la formación en consumo de medios, en la recepción crítica de contenidos y el papel que los padres deben asumir como guías en el proceso de consumo televisivo de sus hijos/as.

\section{Impacto de la televisión en los niños}

El $60,47 \%$ de los niños y niñas pasan entre 2 y 4 horas frente al televisor; el 30,24\%, entre 1 y 2 horas; el 6,98\%, entre 4 y 6 horas; y el 2,32\%, de 6 a 8 horas diarias. En resumen, el 90,71\% pasa una media de 2,5 horas frente al televisor cada día. Se observa que los 
niños están expuestos a una cantidad alta de horas de televisión, lo que es un error, de acuerdo con estudios realizados por Sartori (1998) y Yarce (2010). Por ejemplo, frente al tema de los comportamientos violentos existirán múltiples proyectos (Pérez-Ugena y Salas, 2010; Rodríguez, Núñez y Astudillo, 2017; Pérez y Urbina, 2005; Pérez, 2008) que muestran cifras "escalofriantes" relacionadas con el número de horas que los niños pasan frente a las pantallas de la televisión, la cantidad de escenas violentas a las que se ven expuestos y su imitación mediante comportamientos agresivos.

\section{Horarios de consumo de televisión: decisiones y presiones}

Los datos dicen que en la mañana-tarde los niños se encuentran en la escuela, por lo que el 39,54 \% de los menores ven televisión en la jornada de la tarde-noche, seguido de un $20,94 \%$ que ve televisión en la noche. Lo curioso es que 32 de las 43 familias $(74,42$ $\%)$ afirman que sus hijos/as ven programas infantiles. Esto tiene una explicación: aunque no se preguntó a los padres si en el hogar consumían televisión abierta o televisión por cable, la clase social de los encuestados y la masificación de la televisión paga lleva a inferir que los niños y niñas ven programas infantiles de canales internacionales en la jornada de la tarde y la noche, ya que nuestros canales de señal abierta solo transmiten en ese horario novelas, series, realities y noticieros, que son consumidos por el 9,3\% de los menores, una cifra significativa.

Cuando los niños y niñas ven televisión solos, cuando escogen qué ver, el $86,05 \%$ de los padres de familia aseguran que sus hijos/ as ven televisión infantil, seguido de un 6,98\% que ven programas educativos y culturales. Ninguno ve novelas o informativos. Pero la situación cambia cuando los menores se encuentran en compañía de un adulto. El $35 \%$ de los padres afirman que sus hijos/as ven televisión con ellos. Es ahí precisamente cuando el consumo de novelas e informativos crece. La mayoría de los padres afirman que el acuerdo es la forma como escogen qué ver. ¿Tiene un niño de 3 años la capacidad concreta de decidir ver una novela por encima de un programa infantil que le gusta? 
Entre los criterios que juegan al momento de escoger ver un programa juntos (padre, madre, hijos/as), el 67,45 \% de los padres afirma que ven lo que a sus hijos/as les gusta; el 20,94\% reconoce que se escoge por su autoridad como padre o madre; el $7 \%$ de los padres de familia escogen el programa de acuerdo a sus gustos, que de alguna manera es parte de la autoridad, y solamente el $4,66 \%$ de los padres considera que es indiferente. Si se suman los porcentajes se encuentra que el $28 \%$ de los padres reconoce que se ve lo que a ellos les gusta. Ahora bien, también se encuentra que esa "decisión en familia" lleva a que el 39,5\% de los hijos/as de los padres encuestados pasen de ver programas aptos para su edad a consumir novelas, informativos e incluso programas con un contenido exclusivo para adultos.

\section{Qué hacer sin televisión}

La opinión de que la TV es lo único que puede reunir a la familia, que ofrece espacios de diversión y que ayuda a que los niños se mantengan "distraídos", implica cerrar los espacios al diálogo, al juego y al encuentro familiar. Al respecto, el $35 \%$ de los padres considera que si no tuvieran televisión jugarían en casa con sus hijos, el 25,60 \% lo haría fuera de casa, el 23,25 \% dialogaría y en porcentajes menores leería en familia (11,63\%) o iría a comer $(4,66$ $\%)$. Llama la atención que los padres encuestados hablen de qué harían si no hubiera televisión en casa, pero, como la hay, entonces ¿para qué hacer otras cosas? Aquí entra en juego la sana diversión, más allá de lo atractiva que sea la "caja tonta". El valor de la sana diversión consiste en saber elegir actividades que permitan sustituir nuestras labores cotidianas, facilitando el desarrollo físico, intelectual y moral de las personas.

\section{El ideal contra la realidad: el rol que los padres desempeñan frente al consumo de televisión de sus hijos/as}

Con todos los datos antes arrojados, se encontró que los padres encuestados consideran que el rol ideal es ser guía, precisamente el rol que asumen. El $70 \%$ de los padres de familia encuestados 
considera que frente al consumo de televisión de sus hijos deben ser guías; el $21 \%$ piensa que debe ser un acompañante y un 9,30 $\%$ piensa que debe ser un observador pasivo. Para ninguno de los padres es una opción válida ser indiferente frente al tema ya que, por los contenidos, los temas, el lenguaje y los esquemas es necesaria su orientación. Finalmente, el 83,74 \% informa que los padres de familia de niños entre los 3 y 5 años deben, en su orden, explicar, guiar y dialogar frente al consumo de televisión de sus hijos. El 16,28 \% considera que debe aconsejar. Hay conciencia del tema, pero con contradicciones, pues los padres aseguran que deben ser guías de sus hijos, pero en las familias consultadas ven lo que a los adultos les gusta, aunque los contenidos no sean los apropiados para sus hijos. Por esto, ¿están los padres de familia preparados para ser guías frente al consumo de televisión de sus hijos?

\section{Conclusiones}

Los padres de familia que fueron encuestados para esta investigación desempeñan el rol de acompañamiento y orientación, pero no saben si lo hacen bien o mal, pues nunca se les ha enseñado. Aplican lo que vivieron en sus hogares: consumo indiscriminado, recepción pasiva, complicidad en el consumo de televisión. Además, ven la televisión como una herramienta útil en casa, que ayuda a cuidar a los niños y los distrae mientras realizan otras actividades; y cuando se preguntan por qué sus hijos/as actúan de cierta manera encuentran la culpable fácilmente: la televisión.

Es visible la tarea de formar en la recepción crítica de la televisión, acompañada de la implementación de alternativas como actividades lúdicas y culturales dentro y fuera de casa, y que los niños tengan a la mano otras opciones de entretenimiento, teniendo en cuenta que de los padres depende el buen uso de la "pantalla mágica".

Refiriéndose al cine, pero también a la televisión, Rivera (2010) afirma que es fundamental, entonces, educar para la recepción y la 
percepción de imágenes, pues esta es la única posibilidad de educar a los espectadores para que exijan mejor calidad.

Los padres consultados ven la televisión como una herramienta de entretenimiento en el hogar que ayuda a mantener a sus hijos "distraídos", pero hay certeza de que esa no es la ruta. Son conscientes de que no todo lo que sale en televisión es adecuado para ellos, pero, aunque quieren ayudarles a entender que lo que ven es "de mentiras", no saben cómo hacerlo sin que esa tarea se torne en un conflicto.

Algunos de los temas que deberían trabajarse en casa son:

- Compartir la televisión en el hogar y generar un diálogo alrededor de los contenidos. Así se podrán ver programas juntos para acompañar o para informar por qué usted como padre considera que algún contenido no es apto. Esto incluye la publicidad.

- Conocer qué programas ven sus hijos/as y saber qué tipos de mensajes dan. De esa manera los padres podrán entrar más fácilmente en una conversación con los niños sobre esos programas.

- Es fundamental establecer un límite de tiempo de exposición a la televisión para que existan unas reglas mínimas frente al aparato.

- Enseñar con el ejemplo: si el padre vive "pegado" al televisor no tiene autoridad para prohibirla a sus hijos/as.

Por otro lado, es necesario diseñar talleres de formación para padres acerca de la recepción crítica de medios y la formación en mediación y orientación frente a los contenidos de todos los medios, especialmente la televisión por su impacto y penetración. Esos talleres deben ser prácticos, con ejemplos de programas, estudios y resultados. No se trata de hacer de la televisión un ene- 
migo en casa, sino de comprender la naturaleza del medio, del negocio y de cómo aprovechar la televisión como herramienta de entretenimiento, diversión e información, pero también de formación. La observación, la reflexión, la discusión y la participación son fundamentales para alimentar y retroalimentar el debate en torno a este importante tema.

Algunas de las áreas que deberían abarcarse son:

- La televisión como medio: su historia, desarrollo, papel dentro y fuera de casa.

- Los contenidos y su impacto: consumo, recepción pasiva y recepción activa, mensaje.

- La relación niños-televisión: cómo ven los niños la televisión y contenidos para ellos.

- La televisión en familia: incentivar un espacio de entretenimiento, pero también un momento de reflexión. El papel de los padres como orientadores del consumo de televisión en casa.

- Recepción crítica: desglose de imágenes y mensajes. Cómo ser críticos.

\section{Referencias bibliográficas}

Albero, M. (1996). Televisión y contextos sociales en la infancia: hábitos televisivos y juego infantil. Comunicar, 6, 129-139. Recuperado de http:// www.redalyc.org/articulo.oa?id $=15800626$

Altarejos, F. (2002). La relación familia-escuela. ESE: Estudios Sobre Educación, 3(1), 113-120. Recuperado de http://dadun.unav.edu/ bitstream/10171/8235/1/Nb.pdf 
Cabero, J. (1997). Investigaciones sobre el consumo de televisión. En J. Aguaded (Ed.), La otra mirada a la tele: pistas para un consumo inteligente de la televisión (pp. 69-78). Sevilla: Junta de Andalucía. Recuperado de http://www.grupocomunicar.com/contenidos/pdf/laotra-mirada-de-la-tele/10-cabero.pdf

Castillo, M. (2004). Guía para la formulación de proyectos de investigación. Bogotá: Cooperativa Editorial Magisterio.

Castro, G. (2007). Aprendamos a ver TV: guía para padres y maestros. Bogotá: Comisión Nacional de Televisión.

Coloma, J. (1993). La familia como ámbito de socialización de los hijos. En J. Quintana (Ed.), Pedagogía familiar (pp. 31-44). Madrid: Narcea.

Comellas, J. (2009). Familia y escuela: compartir la educación. Barcelona: Graó.

Comisión Nacional de Televisión. (2008). Gran Encuesta de la Televisión en Colombia. Bogotá: CNTV. Recuperado de http://static.iris.net.co/ semana/upload/documents/Doc-1774_20081024.pdf

Díaz, J. (2014). Televisión, familia e infancia: estrategias y planes de acción. Bogotá: Universidad de La Sabana.

Pérez Contreras, M. (2008). Infancia y violencia en medios de comunicación: Aproximación a un aspecto de la educación informal. Boletín mexicano de derecho comparado, 41(121), 315-356. Recuperado de https://revistas.juridicas.unam.mx/index.php/derecho-comparado/ article/view/3966

Pérez, F. y Urbina, S. (2005). Violencia en los dibujos animados de ayer y hoy. Comunicar, 13(25), 1-11. Recuperado de https://www. revistacomunicar.com/index.php?contenido=detalles \&numero=25\&arti culo=25-2005-077

Pérez-Ugena, Á., Menor, J. y Salas, Á. (2010). Violencia en televisión: análisis de la programación en horario infantil. Comunicar, 18(35), 105- 
112. Recuperado de https://www.redalyc.org/pdf/158/15815042013. pdf

Ramírez, M. (2007). La importancia de la televisión como espacio para la construcción de la sociedad: el caso de la radio y televisión de Andalucía, España. Global Media Journal 4(8), 1-17. Recuperado de https://idus. us.es/handle/11441/25409

Río, P. del, Río, M. del y Álvarez, A. (2004). Pigmalión: informe sobre el impacto de la televisión en la infancia. Madrid: Fundación sobre Infancia y Aprendizaje.

Rivera, J. (2010). Cine: recetas y símbolos. Medellín: Universidad de Medellín.

Rodríguez, A. (2011). La relación de los niños desde el nacimiento hasta los treinta y seis meses y la televisión. Perspectivas de Investigación y Debates (1999-2010). Recuperado de https://www.mincultura.gov.co/ SiteAssets/Comunicaciones/La\%20relaci\%C3\%B3n\%20de\%20los\%20 ni\%C3\%B1os\%20desde\%20el\%20nacimiento\%20hasta\%20los\%20 $36 \% 20$ meses\%20y\%20la\%20televisi\%C3\%B3n.pdf

Rodríguez, C., Núñez, V. y Astudillo, E. (2017). Consumo televisivo de audiencias infantiles: un estudio cualitativo con estudiantes chilenosChile.COMUNI@CCION: Revista de Investigación en Comunicación y Desarrollo, 8(2), 105-115. Recuperado de https://www.redalyc.org/ pdf/4498/449854118004.pdf

Sampieri, R., Fernández, C. y Baptista, P. (2010). Metodología de la investigación (5.a ed.). México: McGraw Hill.

Sartori, G. (1998). El homo videns. Madrid: Taurus.

Sedeño, A. (2005). Emoción y hábitos de los niños frente a la televisión. Comunicar, 25(1), 1-10. Recuperado de http://www.redalyc.org/articulo. oa? id=15825055 
Valle, A. del (2006). Los menores ante la televisión: una reflexión pendiente. Revista Educación, 15(28), 83-103. Recuperado de http:// revistas.pucp.edu.pe/index.php/educacion/article/view/2050

Wartella, E., Richert, R. y Robb, M. (2010). Babies, television and video: how did we get here? Development Review, 30(2), 116-127. Recuperado de https://www.researchgate.net/publication/222750011_Babies_television_and_videos_How_did_we_get_here

Wolf, M. (1994). Los efectos sociales de los media. Barcelona: Paidós.

Yarce, J. (1993). Televisión y familia. Bogotá: Ediciones Palabra.

Yarce, J. (2010). Tvnetgeneration, la generación interactiva: desafíos para la familia. Bogotá: Planeta. 